Research Article

\title{
Assessment of Acoustic Emission and Triaxial Mechanical Properties of Rock-Cemented Tailings Matrix Composites
}

\author{
Shuai Cao $\mathbb{D}^{1},{ }^{1,2}$ Erol Yilmaz $\mathbb{D}^{3}{ }^{3}$ Weidong Song, ${ }^{1,2}$ and Gaili Xue $\mathrm{C}^{1,2}$ \\ ${ }^{1}$ State Key Laboratory of High-Efficient Mining and Safety of Metal Mines of Ministry of Education, \\ University of Science and Technology Beijing, Beijing 100083, China \\ ${ }^{2}$ School of Civil and Resources Engineering, University of Science and Technology Beijing, Beijing 100083, China \\ ${ }^{3}$ First Quantum Minerals Ltd., Cayeli Bakir Isletmeleri A.S., P. O. Box 42, Madenli, Cayeli, Rize TR53200, Turkey \\ Correspondence should be addressed to Erol Yilmaz; yilmazer@fqml.com
}

Received 16 April 2019; Revised 24 August 2019; Accepted 30 September 2019; Published 16 October 2019

Academic Editor: Jun Liu

Copyright (C) 2019 Shuai Cao et al. This is an open access article distributed under the Creative Commons Attribution License, which permits unrestricted use, distribution, and reproduction in any medium, provided the original work is properly cited.

\begin{abstract}
Acoustic emission (AE) test is a powerful technique for examining the sounds of cracks growing, breaking, and other modes of damage in cementitious materials deforming under stress, such as rock-cemented tailings matrix composites (RCTMC). RCTMC, an engineered mixture of tailings, cement, rock, and water, is widely used to fulfill numerous important roles at underground mine sites as a construction material and a ground support tool. To study the mechanical strength and AE properties of RCTMC, compression testing was carried out using a triaxial compression test system (TAW-2000) and AE monitoring system (PCI-2), and the failure modes of samples were also examined. Results have shown that (1) the failure process of RCTMC samples can be divided into six main stages: compaction, linear elastic characteristic, crack growth, primary damage development, cemented tailings backfill withstand stress zone, and secondary damage development stage. CTB has the strengthening effect on mechanical strength of rock; (2) the AE process can be also divided into six main stages: the prepeak quiescence period, the elastic energy reserve period, the first destruction development $\mathrm{AE}$ area, the secondary energy reserve period, the second damage development stage, and the postpeak calm period; and (3) samples' cumulative ring count is "stepped" distribution over time, and the ring count has entered the postpeak flat stage after many active periods. The process of RCTMC samples from tensile to shear failure mode is represented by numerical simulation. Finally, the obtained experimental results can offer a useful reference for the further study of the mechanism of the surrounding rock and cemented tailings backfill structure.
\end{abstract}

\section{Introduction}

Mining is of great importance on the economic development of many countries and is largely divided into surface and underground mining. Underground mining is an effective technique used to extract the ores from the earth's crust, involving many methods such as open stoping, caving, and filling. Cemented tailings backfill (CTB) or cemented paste backfill (CPB) is widely used in most modern underground mine sites owing to its several roles. It can be used as a construction material, a major ground support tool, and a key mine waste treatment technique $[1,2]$. Indeed, this technique allows mine operators to reduce their tailings disposal and rehabilitation costs, and offer the mining operations more environmentally friendly [3, 4]. By definition,
CTB is an engineered, flow-able, and non-Newtonian material which consists of processing tailings, hydraulic binder, and mixing water [5]. The physical, chemical and mineralogical properties of each component of CTB mix (e.g., tailings, binder, and water) greatly affect its short- and longterm mechanical strength gain, geotechnical, and microstructural performance [6-8]. However, some problems in long-term strength and durability of CTB samples are most often known to be experienced when sulfide-rich tailings are used for paste backfill preparation [9-12]. Various studies have been so far conducted to study the effect of binder type and content, water-to-cement ratio, particle size distribution, and curing conditions (i.e., stress, time, and temperature) on short- and long-term quality and performance of CTB samples via various rock and soil mechanic testing and 
improved laboratory test tools, including uniaxial compression, triaxial compression, rheological, and geotechnical tests [13-16]. There are also other works focusing on mineral and chemical additives which can play a major role in compressive strength properties of paste backfill for a given CTB mixture and curing time [17-19].

In recent years, a new type of mine fill system, namely waste rock-tailings backfill technology, has been introduced for sustainable mining operations. This new technology, also known as RCTMC, was developed on the basis of waste rock mixed with cemented tailings backfill, and offers various operational, technical, and environmental advantages. It appreciably reduces mining waste emissions, effectively improves compressive strength, and stability of the backfill material, and greatly save the backfill-related preparation and operational costs [20-22]. The mechanical strength characteristics of RCTMC samples should be investigated after the filling slurry is fully mixed on surface backfilling station and delivered into the underground goaf to come into contact with rock. Several researchers [23] have studied rigorously both laboratory and field performance of waste rock-tailings backfill samples. However, RCTMC technology still needs to be further studied in terms of the backfill mix proportions, and their mixing and transportation properties, and backfill mechanics [24]. Xu et al. [25] experimentally performed a variety of single-axes and triaxial compression tests on thick-walled cylindrical sandstone-containing fillers. They simulated the effect of ground support on the strength, deformation, and failure properties of a circular roadway. Fall and Nasir [26] analyzed the mechanism of cemented tailings backfill and rock for the process of sublevel stoping subsequent paste backfilling through using both laboratory testing and FLAC $^{3 \mathrm{D}}$ numerical simulation software. Cao et al. [27] studied the mechanism between cemented backfill and rock column under the lateral compression status and analyzed the stress process of cemented tailings backfill-waste rock column.

Acoustic emission (AE), an efficient and nondestructive testing method, has been widely used as indoor tests on concrete, coal, and rock mass [28]. Various researchers have shown that AE technology can be effectively used to study the mechanical strength properties and failure modes of cemented waste concrete-coal-crushing gangue backfilling [29-32]. In addition, Feng et al. [33] experimentally studied the dynamic evolution of rock cracks in the loading process by using the $\mathrm{AE}$ equipment. They concluded that the $\mathrm{AE}$ location can reflect the dynamic evolution process of rock cracks. Guo et al. [34] systematically studied the deformation properties and AE activity of concrete through a triaxial compression test, discussing the different failure processes. Li et al. [35] performed a single-axis compression test on salt rock samples under different temperatures. They found that AE well reflects the macroscopic failure of rock samples. These studies have shown that AE monitoring technology has a noticeable advantage when used to study the mechanical properties of coal rocks.

As an efficient mining waste management and filling technology, the coupled waste rock and cemented tailings backfill technology has been successfully used in the underground mine sites and offer some technical, environmental, operational, and financial advantages over other backfilling types [36-38]. However, there are some other aspects of this technology which still need to be further investigated for reaching an efficient backfill technique for mines [39-41]. Thus, the main objective of this paper is to perform an experimental study of waste rock and cemented tailings backfill as an efficient backfilling method, which will provide the best mixture ratio of backfilling aggregate, and achieve effective filling for mine sites. This paper presents the results of the triaxial compressive strength and $\mathrm{AE}$ properties of RCTMC samples prepared by using a self-made acrylic transparent mold. The load confining stress was set to $5 \mathrm{MPa}$ through the PCI-2 AE equipment and a TAW-2000 triaxial tester. The stress-strain distribution and AE characteristics during the loading process of RCTMC samples were investigated to provide a useful reference for the further study of the mechanism of rock and backfill interactions.

\section{Materials and Methods}

2.1. Experiment Background. Figure 1 shows a schematic map of the experimental background used in this study. Underground mining of metal ore breaks the original 3D stress equilibrium state of rock (Figure 1(a)). After the formation of a goaf, the original stress equilibrium state is broken (Figure 1(b)). If this problem is not handled in time, it may cause severe goaf collapse and instability accidents. The coupled waste rock and CTB materials can be successfully used in order to achieve an effective goaf treatment. After the filling slurry enters the goaf, its joint action with ore rock capably controls the stress of underground mines. However, the mechanism of how these two materials (both rock and backfill) interact remains unclear. Considering this engineering background and triaxial test conditions, this study mainly explored the preparation of a test piece of RCTMC samples with external rock and internal backfill samples. The triaxial compression laboratory test works together with a numerical simulation study were performed in this study.

\subsection{Experimental Materials}

2.2.1. Rock Materials. Rock samples were obtained from an underground iron mine located in Hubei Province, China. The rock block is firstly processed into rock specimens with a diameter of $50 \mathrm{~mm}$ and a height of $100 \mathrm{~mm}$ (based on a height-to-diameter ratio of $2: 1$ ) according to ASTM D4543 standard. The rocks are dominated by marble and diorite.

2.2.2. Tailings, Cement, and Water. The tailings sample used during the experiments was also obtained from the same underground iron mine. Chemical composition testing shows that tailings minerals are mainly composed of four minerals: quartz, calcite, and chlorite, supplemented by a small amount of run-of-mine ore such as gypsum, sericite, and pyrite. The physical properties of the processing tailings produced in the mine site are shown in Table 1.

The C-type binder was selected as the basic binding agent used for CTB preparing. The C-type included 


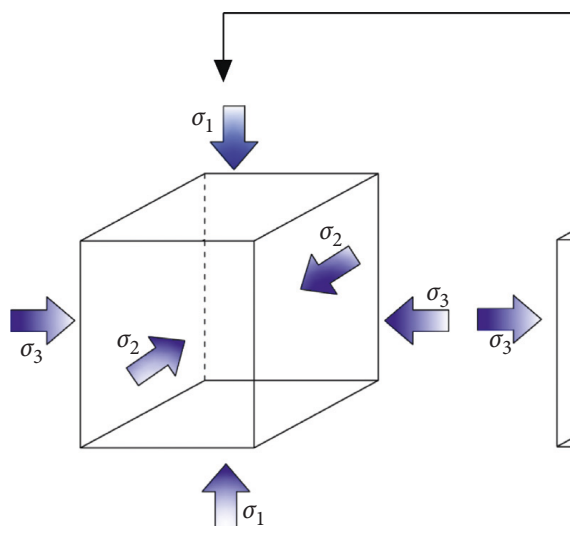

(a)

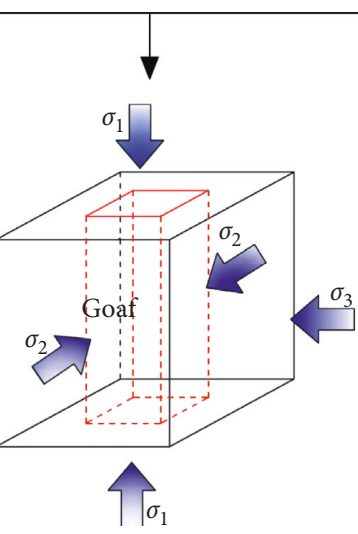

(b)

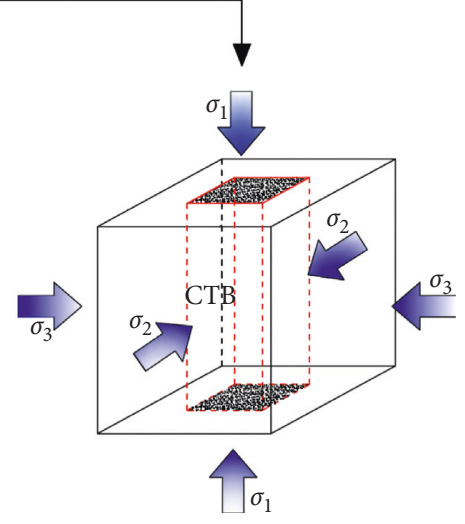

(c)

FIgURE 1: Schematic diagram of the experiment system. (a) Initial stress. (b) Single goaf. (c) Goaf backfill.

TABLE 1: Chemical composition of the tested tailings material.

\begin{tabular}{lccccccc}
\hline Chemical composition & $\mathrm{SiO}_{2}$ & $\mathrm{TFe}$ & $\mathrm{SFe}$ & $\mathrm{CaO}$ & $\mathrm{FeO}$ & $\mathrm{Al}_{2} \mathrm{O}_{3}$ & $\mathrm{MgO}^{2}$ \\
\hline Content (\%) & 26.30 & 20.79 & 20.02 & 12.45 & 10.90 & 6.07 & 5.55 \\
Chemical composition & $\mathrm{S}$ & $\mathrm{Ag}$ & $\mathrm{TiO}_{2}$ & $\mathrm{Cu}$ & $\mathrm{MnO}$ & $\mathrm{P}$ & $\mathrm{Au}$ \\
Content (\%) & 1.315 & 0.38 & 0.232 & 0.228 & 0.164 & 0.15 \\
Chemical composition & $\mathrm{SrO}$ & $\mathrm{Zn}$ & $\mathrm{V}_{2} \mathrm{O}_{5}$ & $\mathrm{Co}$ & $\mathrm{Ni}$ & 0.101 \\
Content (\%) & 0.046 & 0.026 & 0.023 & 0.013 & 0.10 & $\mathrm{~Pb}$ & 0.006 \\
\hline
\end{tabular}

abundant contents of $\mathrm{SiO}_{2}(22.31 \%)$ and $\mathrm{CaO}(61.48 \%)$, as well as amounts of $\mathrm{Fe}_{2} \mathrm{O}_{3}$ (3.02\%), $\mathrm{SO}_{3}(1.81 \%)$, and $\mathrm{MgO}$ (3.18\%). Tap water was used to mix the tailings and C-type cement. The tailings, binder, and water were mixed for 15 minutes in order to obtain CTB mixture with the desired consistency.

The raw materials used in this study include full tailings, diorite rock processing test piece, and C-type rubber aggregate. The coring sample with diorite as the main body was extracted from the rock mass around the deep ore body of a Chinese metal mine. The obtained coring sample was then processed into a standard sample of $\varnothing 50 \mathrm{~mm} \times 100 \mathrm{~mm}$ according to the standard for the soil test method (GB/T 50123-1999) [42]. The standard sample was reprocessed once more in order to form a hollow rock cylinder with an inner diameter of $\varnothing 25 \mathrm{~mm}$, as shown in Figure 2 .

\subsection{Experimental Equipment. During experiments, a triaxial} test system was used in order to measure the mechanical properties of deformable RCTMC samples according to DZ/ T 0276.20-2015 [43]. Application of different compressive stresses during triaxial testing leads to different shear stresses; loads can be increased and deflections monitored until failure of the sample. From triaxial compression testing, it is possible to obtain some information on material parameters of RCTMC sample, such as the angle of shear resistance, apparent cohesion, and dilation angle. These parameters are used in numerical modeling for estimating how RCTMC sample behaves in a larger-scale engineering application. In this regard, the triaxial test system, clearly shown in Figure 3, included loading, deformation monitoring, and $\mathrm{AE}$ monitoring equipment.
2.3.1. Loading Equipment. TAW-2000 microcomputer-controlled electro-hydraulic servo rigid rock triaxial tester produced by Changchun Chaoyang was selected for this experimental work. The confining stress was $100 \mathrm{MPa}$, the axial displacement was $200 \mathrm{~mm}$, and the deformation precision was $\leq \pm 0.1 \%$.

2.3.2. Deformation Monitoring Equipment. An extension meter manufactured by Changchun Chaoyang Test Equipment Co., Ltd was used to determine accurately the small axial deformation and radial deformation required by the Poisson ratio of rock wrapped cemented tailings backfill samples. The maximum axial and radial deformation of extension meter is $4 \mathrm{~mm}$, and standard samples $\varnothing 50 \mathrm{~mm} \times 100 \mathrm{~mm}$ measured.

2.3.3. AE Monitoring Equipment. The PCI-2 AE monitoring system of Physical Acoustics Corporation (PAC) was used for studying the $\mathrm{AE}$ behavior of rock-wrapped cemented tailings backfill samples according to JB/T 11603.1-2013 [44]. The threshold of the two-channel preamp was $40 \mathrm{~dB}$. Vaseline was used as a coupler to load the cavity and acoustic emission probe, and the probe was fixed on the loading cavity by tape.

2.4. Experimental Process. In the design and accomplishment of tests, the following test protocol was implemented (1) To use two types of gray sand ratio and two types of mass concentration of the cemented tailings backfill slurry, the bottom of the hollow cylinder was equipped with a cushion sleeve. Then, different solid concentrations and proportions of the cemented tailings backfill slurry were injected into the 


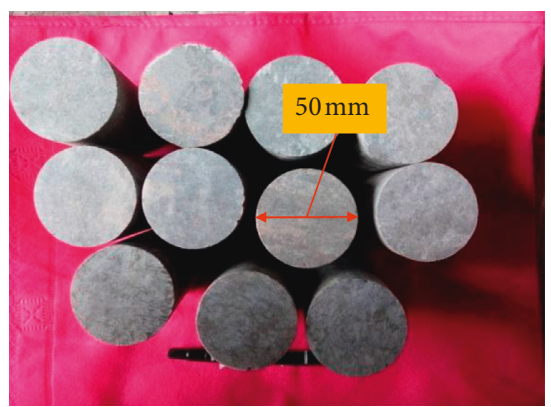

(a)

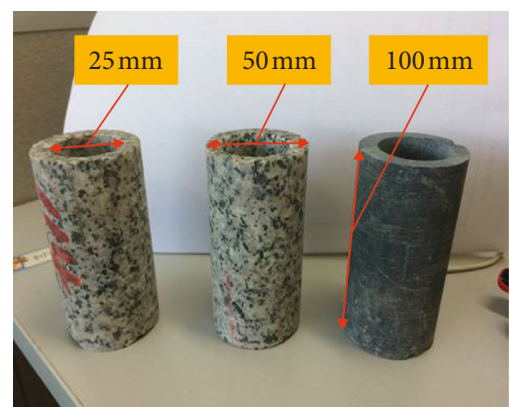

(b)

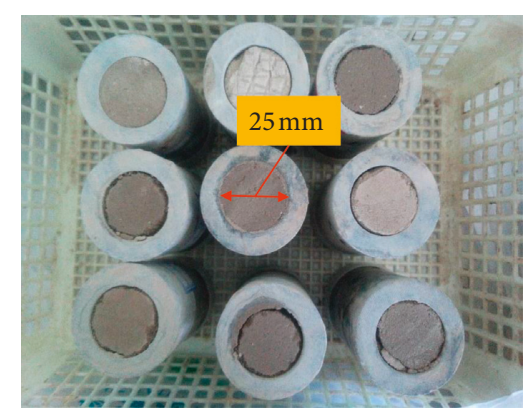

(c)

Figure 2: Preparation of RCTMC samples at laboratory: (a) rock specimens; (b) thick-walled hollow cylinder specimens; and (c) RCTMC samples.
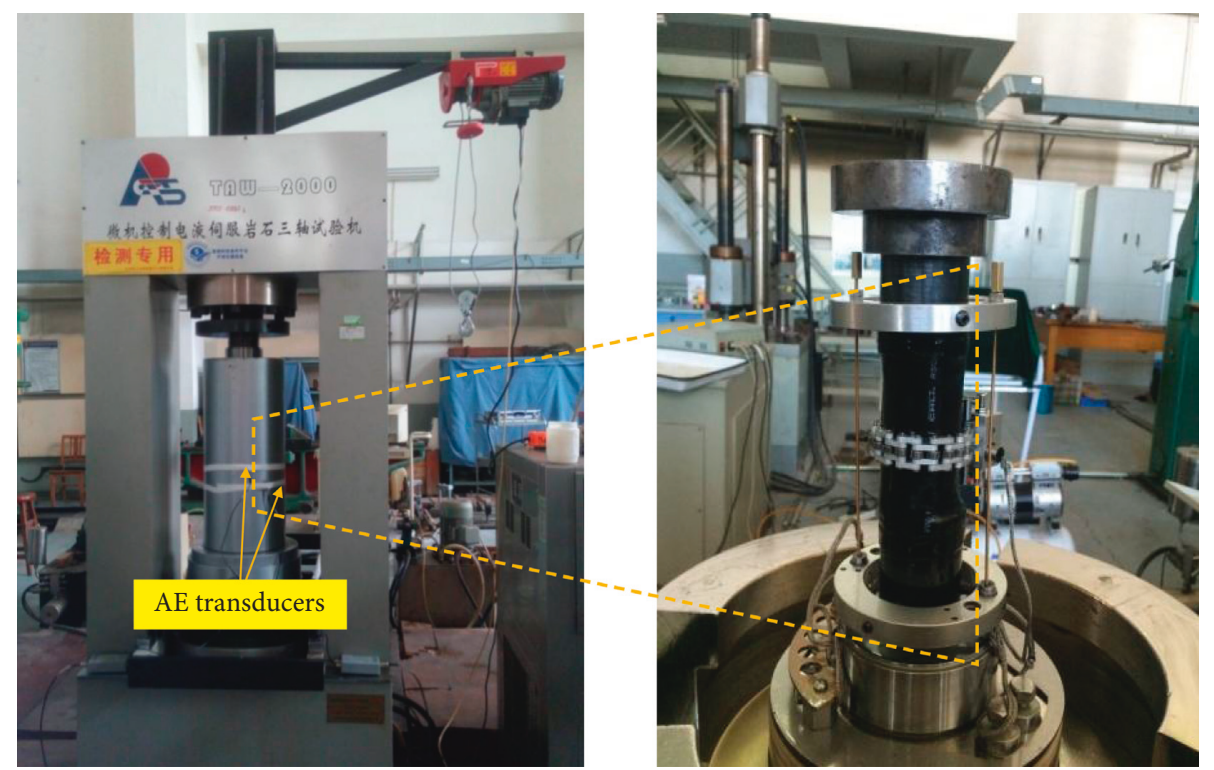

Figure 3: Photo of a triaxial compressive test system equipped with AE monitoring.

hollow cylinder; (2) test samples were kept static for 6 hours after pouring. The surface of the slurry to be filled shrunk and sank. Afterward, the slurry was continuously filled until the filling slurry surface held the line with the coring sample. After the filling slurry was fully cemented and solidified, it was placed in a standard curing room. The curing temperature in the chamber was set to $20 \pm 5^{\circ} \mathrm{C}$, the relative humidity was set to $95 \pm 5 \%$ during a curing time of 28 days; (3) The confining stress considered for triaxial test was set to 5.0 MPa to effectively avoid the sudden failure of the sample in reaching peak failure and easily observe the change law of the curve after the peak. A load control was used before the peak strength, and the moving speed was set to $50 \mathrm{~N} / \mathrm{s}$. When the sample reached the yielding stage near the peak strength, displacement control was used, and the moving speed rate was set to $0.03 \mathrm{~mm} / \mathrm{min}$.

\section{Results and Discussion}

3.1. Analysis of Triaxial Test Results. To measure the mechanical properties of cemented tailings backfills in the mined-out openings or stopes, the triaxial compression tests are often used to obtain mechanical parameters such as cohesion and internal friction angle of rocks or other materials. In this regard, triaxial compression tests were performed on RCTMC sample and standard rock sample (RS), and the test data are shown in Table 2. Here the "\%" means the percentage of solids mass of filled slurry.

The experimental results given in Table 1 demonstrate that when the gray sand ratio was $1: 6$, the triaxial compression strength of RCTMC sample with $70 \%$ slurry concentration was $112.1 \mathrm{MPa}$. The peak strength increased by $12.8 \%$ compared with that of $65 \%$ slurry concentration. When the gray sand ratio was $1: 8$, the peak strength of $65 \%$ and $70 \%$ slurry concentration was $105.5 \mathrm{MPa}$ and $93.8 \mathrm{MPa}$, respectively. Meanwhile, under the same test conditions, the triaxial compression strength of RS sample reached $142 \mathrm{MPa}$ is higher than that of RCTMC samples. Regardless of, whether $1: 6$ or $1: 8$ of RCTMC samples are used, the residual strength value corresponding to $70 \%$ slurry concentration was higher than that of $65 \%$ slurry concentration, but it is higher than the residual strength value of $29.5 \mathrm{MPa}$ 
TABLE 2: Triaxial compression strength of RCTMC and RS specimens in these tests.

\begin{tabular}{lcccc}
\hline \multirow{2}{*}{ Specimen name } & Cement-to-tailings ratio & \multicolumn{2}{c}{ Slurry content, \% (peak) } & \multicolumn{2}{c}{ Slurry content, \% (remnant) } \\
& & 65 & 70 & 65 \\
\hline \multirow{2}{*}{ RCTMC sample } & $1: 6$ & $99.4 \mathrm{MPa}$ & $112.1 \mathrm{MPa}$ & $37.3 \mathrm{MPa}$ \\
RS sample & $1: 8$ & $93.8 \mathrm{MPa}$ & $105.5 \mathrm{MPa}$ & $35.0 \mathrm{MPa}$ \\
\hline
\end{tabular}

of RS. The reason is that after RS reached the peak strength, the elastic energy of the internal agglomeration was released suddenly, and the rigid parameters of the damaged rock block were quite large. Consequently, the residual strength could not be effectively accumulated. When rock wrapped cemented tailings backfill samples were placed under confining stress, the external rock was destroyed, and the cemented tailings backfill sample was a flexible material that could absorb the elastoplastic energy. Consequently, the residual strength after the peak strength was relatively high, indicating that cemented tailings backfill sample had a considerable effect on improving the ultimate compressive strength of the rock.

3.2. Analysis of Stress-Strain Relationship Curves. The stressstrain relationship curves of different RCTMC samples are obviously shown in Figure 4. To elaborate the failure (damage) process of rock wrapped cemented tailings backfill samples, the stress-strain curves of $1: 6$ gray sand ratio and 70 wt. \% slurry concentration samples were taken as examples, as shown in Figure 5.

Figure 5 shows that the failure stage of rock-wrapped cemented tailings backfill samples were broadly divided into six stages as follows:

(1) Compaction stage (A-B section): Similar to the stress-strain relationship curves of rock or cemented tailings backfill, this stage corresponds to the compaction stage of RCTMC sample. At this stage, the rock and filling were in the axial compression state, the internal pore cracks and pores were closed, and the curve was characterized by a concave shape. However, because the stiffness of the rock was fairly larger than that of cemented tailings backfill, the deformation in the compaction stage was small. The porosity of cemented tailings backfill samples was large, and the fracture of the backfill hole was not completely closed;

(2) Linear elasticity stage (B-C section): The bearing of this specific stage is still the external rock inclusions. Although the corresponding rock appeared to have stress concentration, it did not reach the threshold of failure. In addition, the overall performance showed linear characteristics;

(3) Crack propagation stage (C-D section): In this stage, the crack propagation in the outer rock inclusion exceeds its threshold. Although the internal wrapping cemented backfill provided partial resistance, the forced load was small, and the damage of RCTMC sample was openly manifested as the
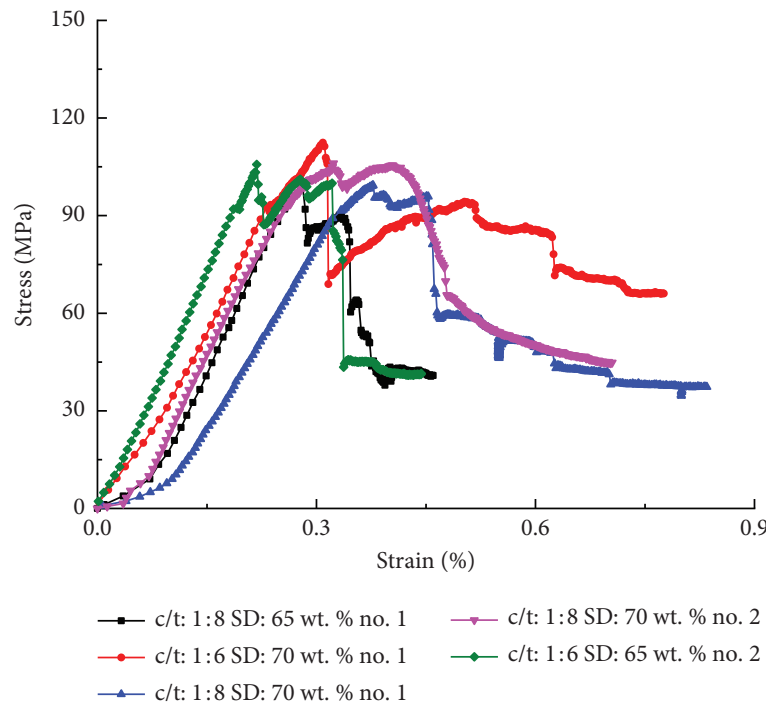

FIgURE 4: Stress-strain curves of different types of RCTMC samples.

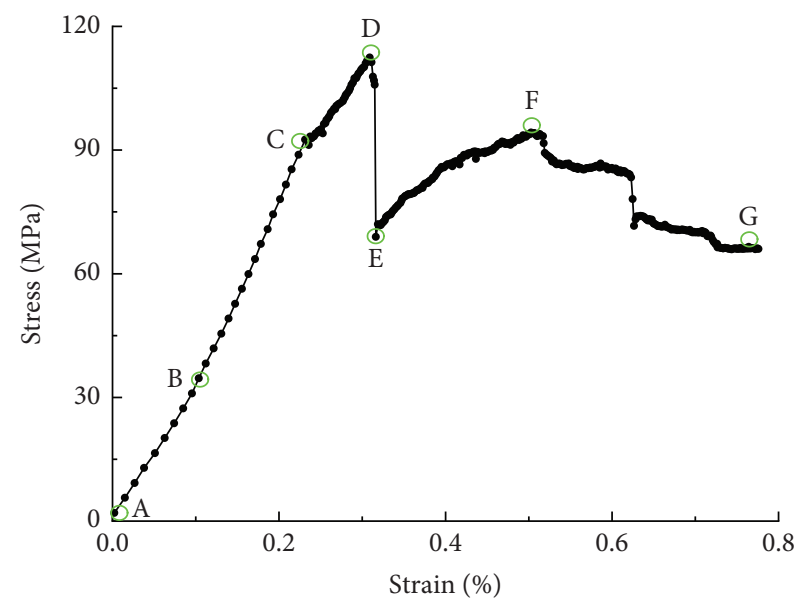

Figure 5: A sample stress-strain relationship curve of RCTMC samples: compaction stage (A-B section); linear elasticity stage (B$\mathrm{C}$ section); crack propagation stage (C-D section); initial failure development stage (D-E section); cemented backfill bearing stress stage (E-F section); and secondary failure development stage (F-G section).

destruction of the external rock. The curve was characterized by a convex shape;

(4) Initial failure development stage (D-E section): Different from the failure stage of a complete rock or cemented tailings backfill sample, RCTMC sample, after reaching the peak compressive strength, was the 
first to develop and penetrate the external rock cracks. Then, the external rock was seriously damaged and basically in the state of instability;

(5) Cemented backfill bearing stress stage (E-F section). Figure 5 shows that when the external rock reached the peak strength, the corresponding axial strain was less than $0.3 \mathrm{~mm}$. According to the preliminary mechanical testing, the strain of the peak strength of cemented tailings backfill samples was much greater than $0.3 \mathrm{~mm}$. The cemented tailings backfill sample in this stage was actually in the compaction or elastic stage. Thus, the cemented tailings backfill sample began to bear, and RCTMC sample showed a secondary increase in stress;

(6) Secondary failure development stage (F-G section): The internal CTB sample reached the peak strength at the $\mathrm{F}$ point. After the peak point, it was characterized by the large expansion and cut-through stage of the cracks within the backfill sample. The stress was quickly reduced in a short period until the entire specimen failed.

3.3. AE Characteristics of RCTMC Samples. Figure 6 illustrates the ring count-axial stress-time relationship curve of No. 2 rock wrapped cemented tailings sample with $1: 8 \mathrm{ce}$ ment-to-tailings ratio and 70\% slurry concentration and No. 1 rock wrapped cemented tailings backfill sample with 1:6 cement-to-tailings ratio and 70\% slurry content. Figure 6(a) shows that the AE monitoring process was divided into six stages, namely, prepeak calm, elastic energy reserve, initial failure development $\mathrm{AE}$ compaction, secondary energy reserve, secondary failure development, and postpeak calm. Figure 6(b) shows that the initial peak strength of rockwrapped cemented tailings backfill sample was 107.3 MPa. When the stress value reached $90 \%$ of the overall peak strength, the ring count increased to 1877 times/s.

After the initial peak triaxial strength entered the external rock failure expansion stage, the corresponding AE ring count became more compact than before. When the external rock was destroyed, the axial strain was enlarged, and the undestroyed cemented tailings backfill sample bore the stress. The backfill sample was under axial stress until the instability was destroyed. The secondary peak strength was $99.4 \mathrm{MPa}$, and the corresponding ring count increased and reached 983 times/s. This result was because of the fact that the backfill sample was less rigid than the rock itself, and the release of energy during the failure process was slow. After the secondary peak strength, the internal cemented tailings backfill sample was also destroyed under the condition of a certain confining stress. The internal crack of RCTMC samples showed secondary failure development, the crack extension phenomenon was obvious, and the friction between the fractured surfaces made by its AE increasingly active. When the overall residual strength was $44.5 \mathrm{MPa}$, the axial stress changed only marginally over time, and the corresponding ring count became sparse and changed within a small range. One can also state that the role of the AE peaks found in the postpeak regime is closely linked to a snap-back behavior.

\subsection{Failure Modes of RCTMC Samples}

3.4.1. Numerical Simulation Analysis. FLAC ${ }^{3 \mathrm{D}}$ numerical software was used to simulate the triaxial compression strength of RCTMC samples. The inner diameter, outer diameter, and height of the model were 25,50 , and $100 \mathrm{~mm}$, respectively. Group 1 represented the rock sample while Group 2 represented CTB sample. It is also well-known that the mechanical parameters between the rock and CTB are not the same. This simulation used the Mohr-Coulomb failure model. The confining stress was set to $5.0 \mathrm{MPa}$ in consideration of the performance of the indoor simulation computer. The load rate was set to $0.5 \mathrm{~mm} / \mathrm{s}$. The numerical calculation model is shown in Figure 7. The physical mechanical parameters of CTB and rock are shown in Table 3.

Combined with the stress-strain curve and the actual test situation, only the failure process of the external rock sample can be observed. The failure process of the internal wrapped cemented tailings backfill needs to be obtained via simulation. Therefore, the function of the cutting plane in FLAC $^{3 \mathrm{D}}$ was used to analyze the process from the change of stress and plasticity distribution in $Z$ direction and explore the failure process of rock wrapped cemented tailings backfill samples. The simulation results are numerically shown in Figure 8.

In Figure 8, the steps 1000, 2000, 3000, 4000, and 5000 are clearly shown from left to right together with the corresponding $Z$-directional stress and plastic distribution cloud diagram after the equilibrium calculation. Figures 8(a) and 8(b) show that the rock and backfill samples were under stress at the same time during the loading process of RCTMC sample. However, the backfill sample was much less powerful than the external encased rock. From the beginning load to instability failure, its maximum stress was $0.97 \mathrm{MPa}$, and the external surrounding rock $Z$ direction stress was $125.56 \mathrm{MPa}$.

The comparison showed that at the preloading stage, the surrounding rock stress was much higher than that of the backfill because the RCTMC sample inside was the cemented backfill flexible material. Furthermore, the external was a rigid rock material, and the stiffness of the two did not match. In the triaxial compression experiment, with the increase in axial load, the external core bore the main compressive stress. Although the backfill also bore the compressive stress, it was much smaller than the core. At the time of RCTMC sample failure, the strength of the backfill did not reach the simulated set value of $2.5 \mathrm{MPa}$ because of the shear fracture surface that emerged when the external rock was destroyed, thereby causing backfill shear failure along the fracture surface. In Figure 8(c), "shear-n" means "failure in shear now" and "shear-p" stands for "failure in shear in the past." "tension-n" means "failure in tension now" and "tension-p" stands for "failure in tension in the past." "None" means that area where no shear or tensile damage occurred." According to Figure 8(c), as the loading rate setting was high, RCTMC sample showed an obvious loading rate effect during failure and development processes. With the increase in axial load, the stress of the external rock and backfill samples increased; both were represented by 


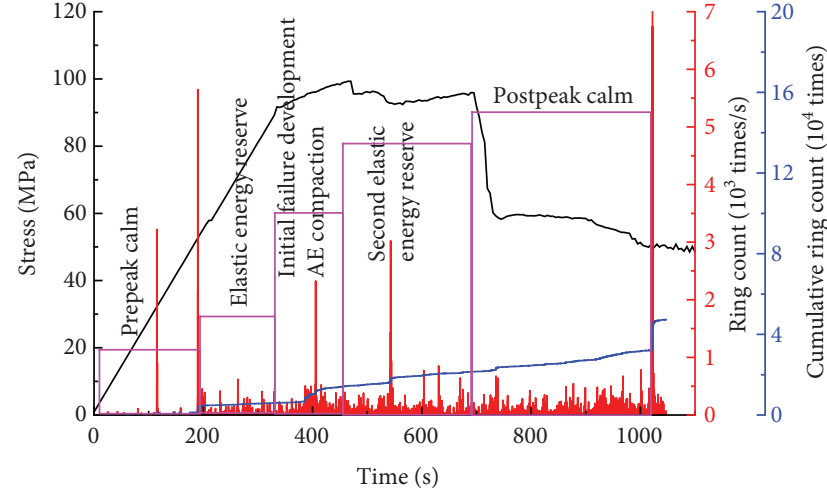

(a)

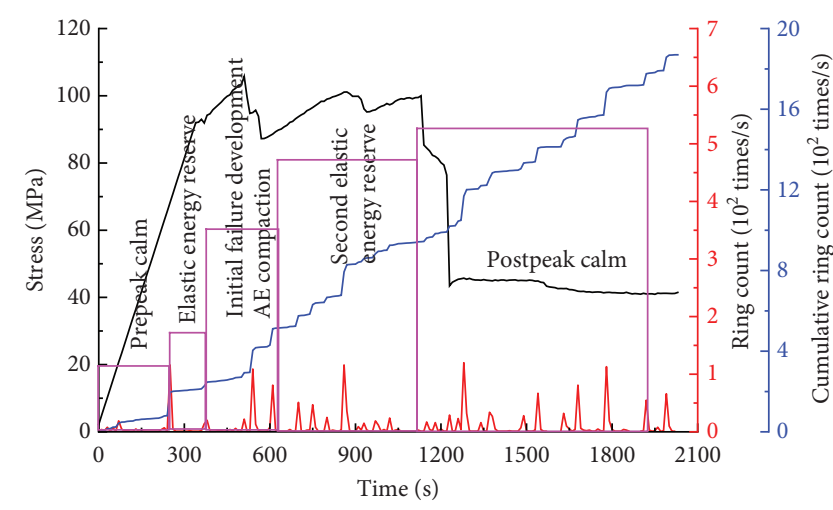

(b)

FIgURE 6: Ring count-axial stress-time relationship curve. (a) No. 2 RCTMC sample with 1:8 cement-to-tailings ratio and 70\% slurry content. (b) No. 1 RCTMC sample with 1:6 cement-to-tailings ratio and 70\% slurry content.

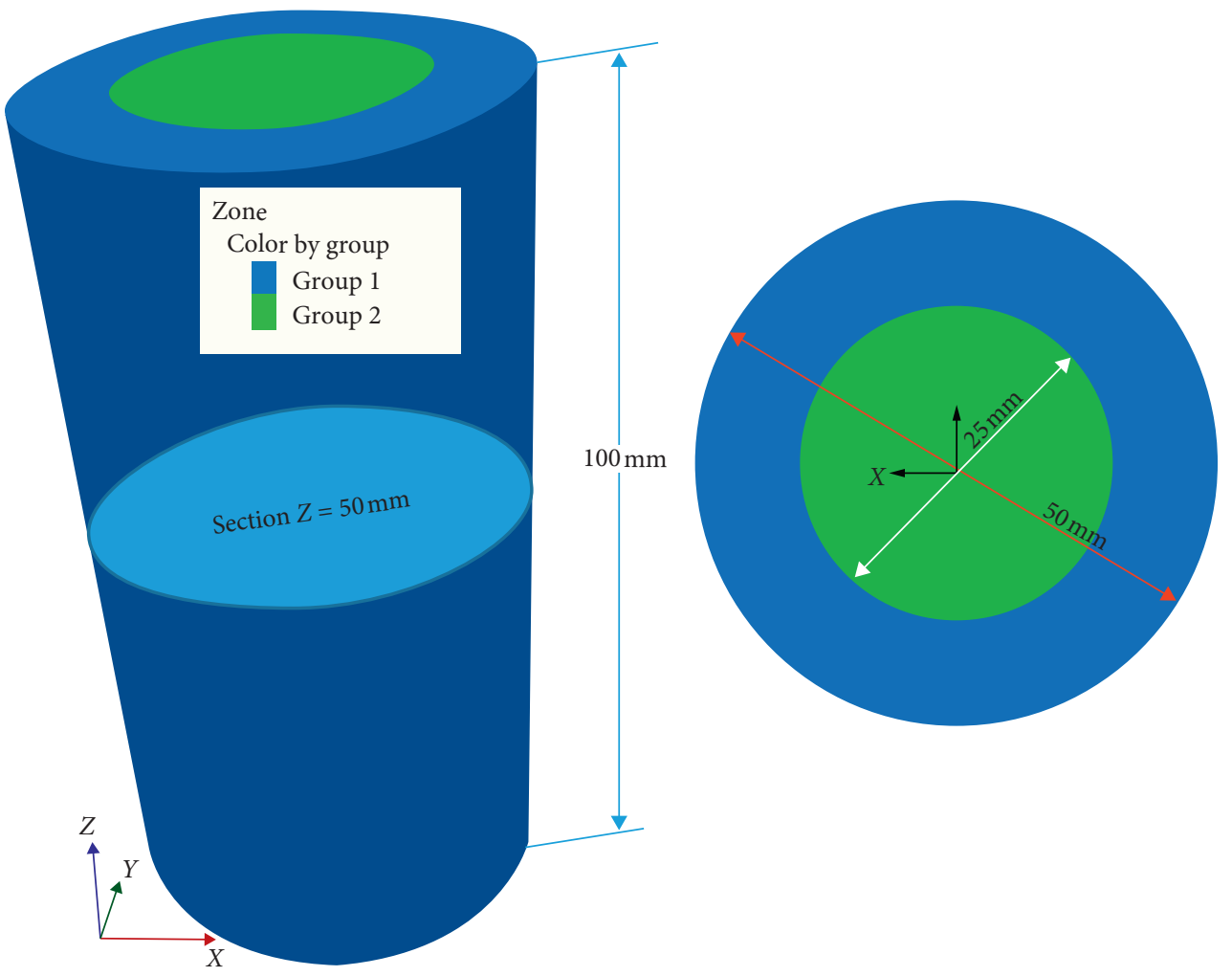

FIgURE 7: Numerical modeling of RCTMC specimen.

conjugate shear failure that gradually changed from tensile failure to an $X$ shape. The ultimate aim of this section is to discover the process of the failure development of RCTMC samples. Although the peak strength of the simulation results is different from that in the room, it still has an advantageous scientific reference value.

3.4.2. Failure Mode of RCTMC Samples. To describe the failure modes of RCTMC samples, its picture was labeled, and the obtained results are clearly shown in Figure 9. Results show that because the hollow rock tube itself contained unidirectional joints, in the triaxial compression process, the hollow rock initially bore the main compression stress. To reach its peak compression strength, the external rock of RCTMC samples along the joint surface exhibited shear failure, and the remaining specimens showed a similar failure law. The reliability of this numerical simulation was verified by the shear failure of the internal cemented tailings backfill sample under the shear stress of the external core joint surface after the failure of the external core.

3.5. Expectations and Limitations. The influence degree of different cement-to-tailings ratio and slurry concentration on strength characteristics of rock was preliminarily 
TABle 3: Physical mechanical parameters of CTB and rock samples.

\begin{tabular}{lccccc}
\hline Type & Elastic modulus $(\mathrm{GPa})$ & Poisson's rate & Cohesion $(\mathrm{MPa})$ & Internal friction angle $\left(^{\circ}\right)$ & Density $\left(\mathrm{kg} / \mathrm{m}^{3}\right)$ \\
\hline CTB & 0.133 & 0.19 & 0.197 & 31 & 2000 \\
Rock & 5.400 & 0.35 & 2.400 & 40 & 4040 \\
\hline
\end{tabular}

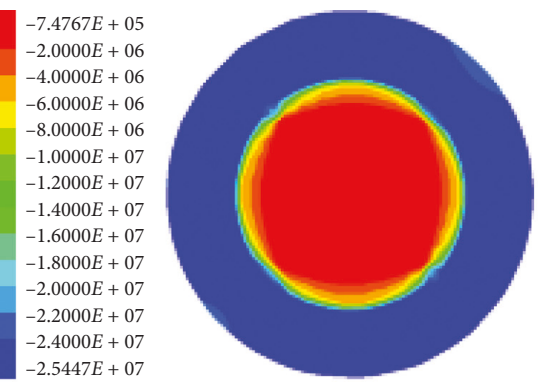

I: step 1000

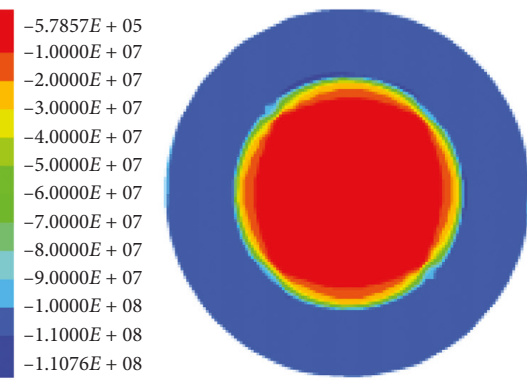

IV: step 4000

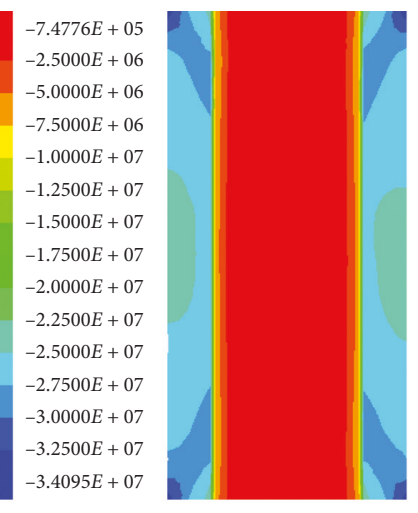

I: step 1000

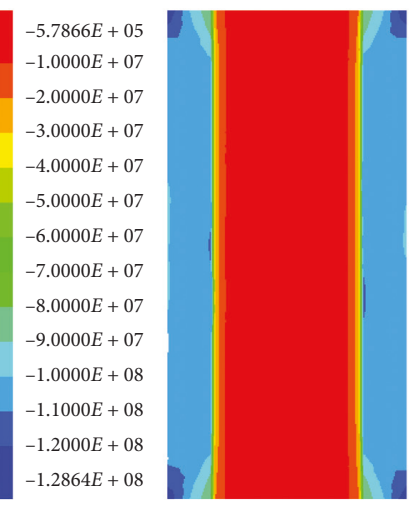

IV: step 4000
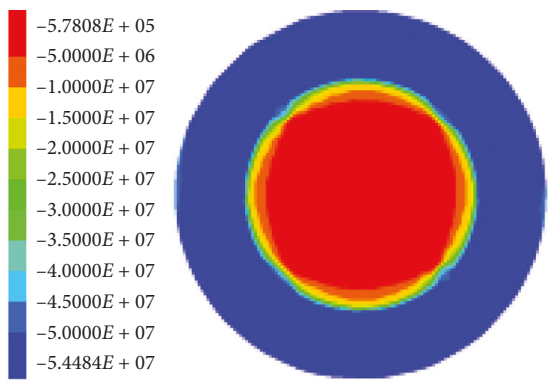

II: step 2000
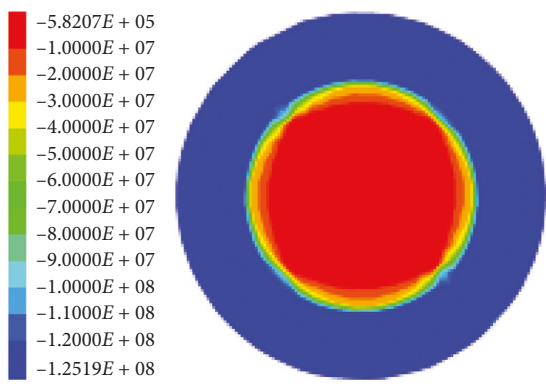

V: step 5000

(a)

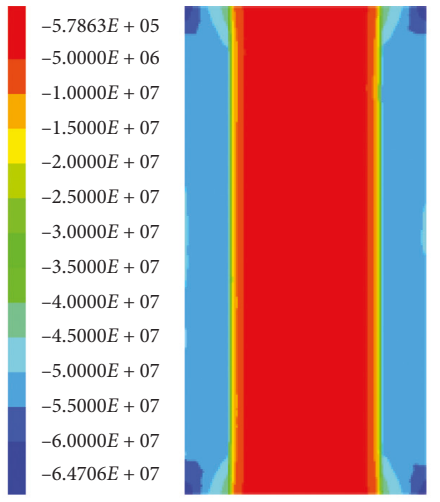

II: step 2000

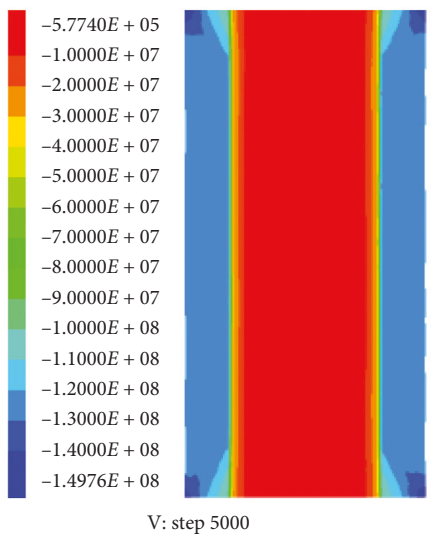

(b)

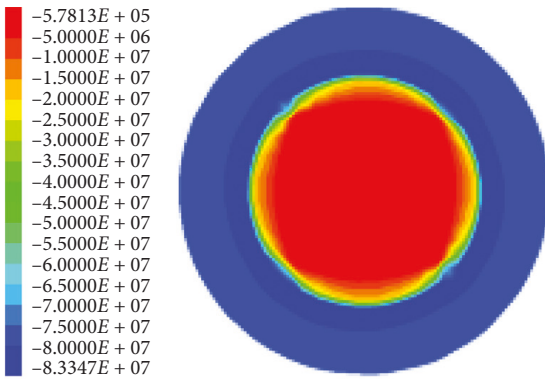

III: step 3000
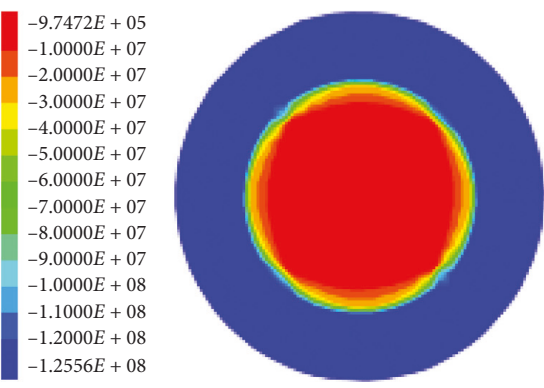

VI: finally

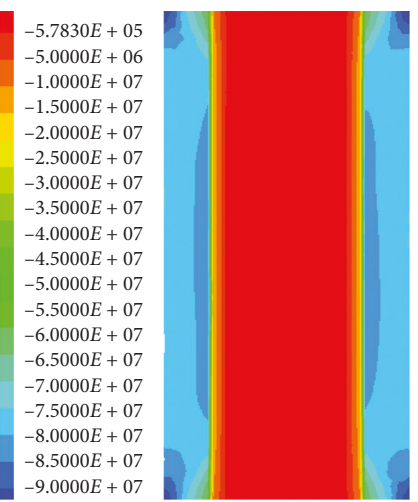

III: step 3000

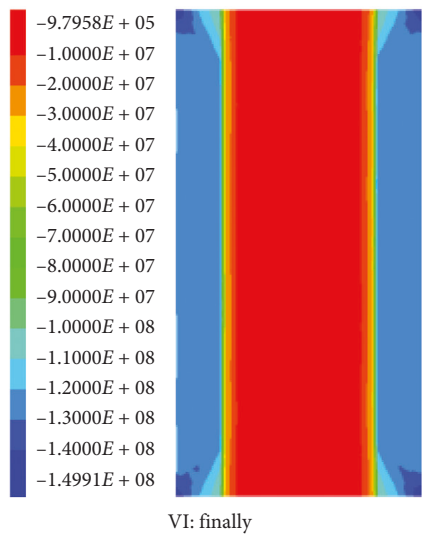

VI: finally

Figure 8: Continued. 


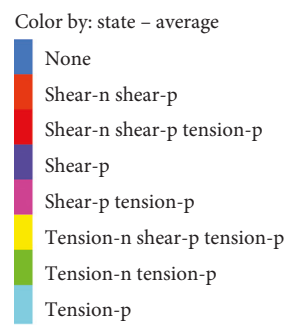

I: step 1000

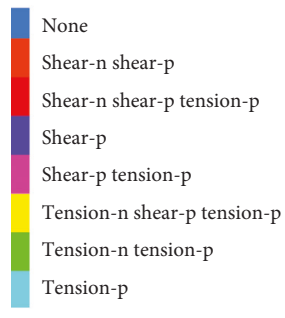

IV: step 4000
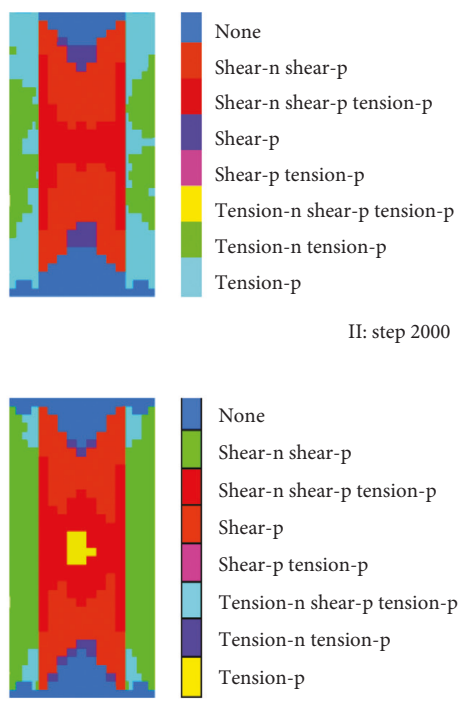

V: step 5000

(c)

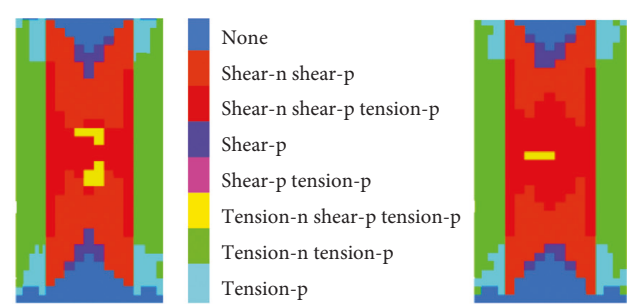

III: step 3000

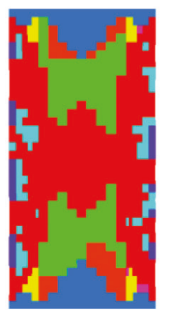

\begin{tabular}{|l} 
None \\
Shear-n shear-p \\
Shear-n shear-p tension-p \\
Shear-p \\
Shear-p tension-p \\
Tension-n shear-p tension-p \\
Tension- $n$ tension-p \\
Tension-p
\end{tabular}

VI: finally

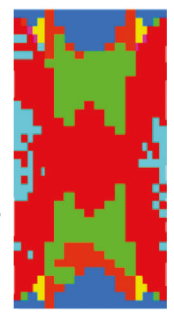

Figure 8: Numerical simulation contour of the loading process of RCTMC specimen. (a) Z-directional stress contour through the point (0, $0,50)$ and the normal coordinate is $(0,0,1)$. Unit: $\mathrm{Pa}$. (b) $Z$-directional stress contour of the $Z$-axis normal profile. Unit: Pa. (c) $Z$-directional plastic zone contour of the $Y$-axis normal profile.

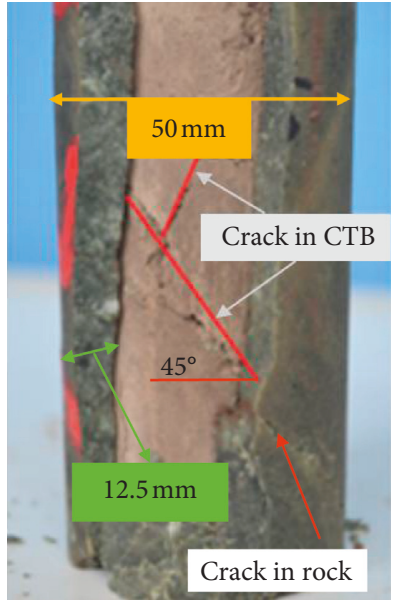

(a)

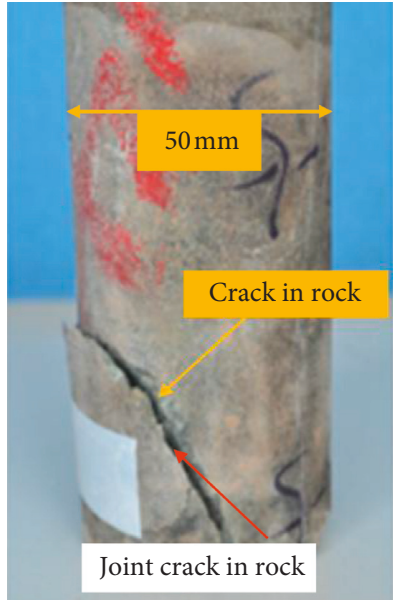

(b)

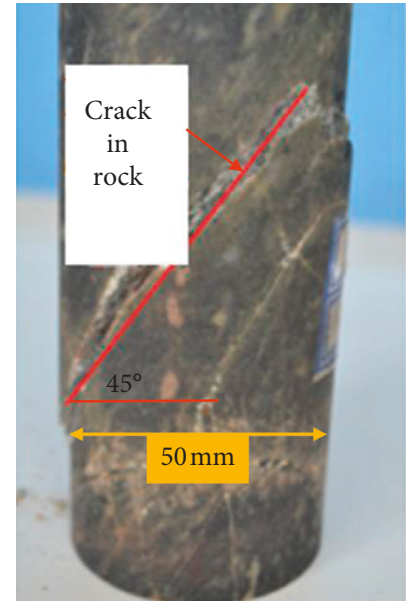

(c)

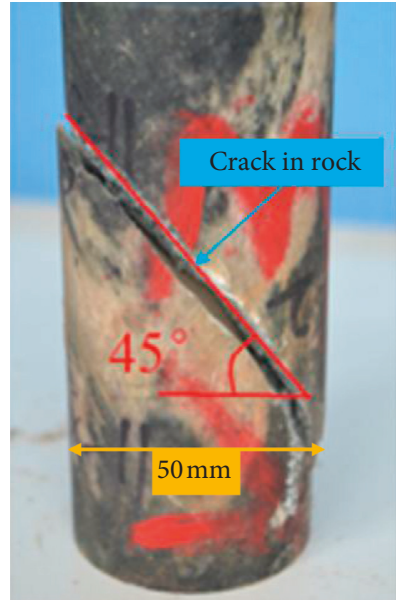

(d)

Figure 9: Failure modes of RCTMC specimens.

explored. Therefore, the triaxial experiment was performed only under the test condition that the confining stress was $5 \mathrm{MPa}$ for all RCTMC samples. The macroscopic mechanical characteristics, microscopic damage failure mechanism, and damage constitutive model of RCTMC samples under different confining stress conditions will be the focus of future studies.

Several limitations were also found in the course of the tests performed. For example, in the processing of hollow rock samples, the mechanical drilling core process easily caused the hollow cylinder wall thickness to be not uniform. This varied thickness may have affected the test results. Hence, in subsequent test specimen processing, laser cutting technology could be used to improve the accuracy of processing rock samples.

\section{Conclusions}

This paper deals the results of an extensive laboratory work undertaken to study the effect of slurry content and cementto-tailings ratio on triaxial strength and AE properties of RCTMC. Samples are prepared by using a self-made acrylic transparent mold and tested by a TAW-2000 triaxial press equipped with PCI-2 AE device for determining the strength and AE properties of the studied samples. A load confining stress was set to $5 \mathrm{MPa}$ for all RCTMC samples. Based on the 
results and discussions, several key conclusions are considered as the main contributions, which are given below:

(1) Cemented backfill had a clear reinforcement effect on peak strength of rock. This showed that backfill had a good effect on goaf stability and could work with the surrounding rock to control the ground stress.

(2) The normal stress applied to RCTMC samples which are used to replicate the wall closure effect had also proved to play a critical factor to backfill behavior.

(3) The RCTMC failure process was divided into prepeak calm, elastic energy reserve, initial failure development $\mathrm{AE}$ compaction, secondary energy reserve and failure development, and postpeak calm stages.

(4) The accumulated AE ring count had a step-type distribution over time, and the ring count underwent multiple active stages before entering the postpeak suspension stage.

(5) The stiffness of the cemented backfill was much lower than that of the rock. Thus, the distribution of accumulated AE characteristics differs from that of a single material.

(6) Numerical analysis showed that RCTMC was represented by conjugate shear failure, presenting a change from tensile failure to an $X$ shape under triaxial compression.

(7) The indoor test confirmed the reliability of the performed numerical simulation under the shear stress of the external core joint surface.

This paper followed a new design technique for mine fill support systems. It contributed to the development of an understanding of the durability behavior of mine fill support systems. In the cut and fill mining method, the backfill stability can be achieved by various special techniques. But, the most key factor for the durability of backfill is the developed friction between rock and backfill itself. The magnitude of the developed friction can be verified by either empirical tests or rock mechanics modeling codes. The factors affecting the durability behavior of RCTMC are the rock wall roughness and the wall closure properties. Nevertheless, the contribution of rock wall roughness on the behavior of RCTMC has not yet been investigated. Consequently, the influence of wall roughness on the stability behavior of RCTMC is most often disregarded in backfill design.

Despite all these works, there are still works which need to be undertaken to clarify this issue: (1) introduction of electronic techniques for the mapping of wall roughness from actual mines needs to be investigated; (2) the effects of blasting and wall joints on backfill stability analysis should also be incorporated in future works; (3) the effect of dosage and type of fiber on the strength and AE properties of shortand long-term cured RCTMC samples from the energy point of view should be investigated in detail; and (4) An industrial computed tomography scanning should be used to more accurately determine the micromechanical behavior of fiber- reinforced RCTMC over different curing times. Adoption of such analyses will grant fast and accurate information to operators or engineers for assessing the rock wall roughness and interface conditions of RCTMC. Better prediction and analysis techniques may lead to safer working conditions in underground mines.

\section{Data Availability}

No data were used to support this study.

\section{Conflicts of Interest}

There are no conflicts of interest regarding the publication of this article.

\section{Acknowledgments}

The authors would like to sincerely acknowledge the financial support of the National Natural Science Foundation of China (51804017), China Postdoctoral Science Foundation (2018M631341), the Open Fund of the Key Laboratory of Ministry of Education for Efficient Mining and Safety of Metal Mines (USTBMSLAB201804), and Fundamental Research Funds for the Central Universities (grant No. FRFTP-17-075A1).

\section{References}

[1] S. Cao, E. Yilmaz, W. Song, E. Yilmaz, and G. Xue, "Loading rate effect on uniaxial compressive strength behavior and acoustic emission properties of cemented tailings backfill," Construction and Building Materials, vol. 213, pp. 313-324, 2019.

[2] M. Mahmoudpour, M. Khamehchiyan, M. R. Nikudel, and M. R. Ghassemi, "Numerical simulation and prediction of regional land subsidence caused by groundwater exploitation in the southwest plain of Tehran, Iran," Engineering Geology, vol. 201, pp. 6-28, 2016.

[3] S. Cao, W. Song, and E. Yilmaz, "Influence of structural factors on uniaxial compressive strength of cemented tailings backfill," Construction and Building Materials, vol. 174, pp. 190-201, 2018.

[4] X. Lu, W. Zhou, X. H. Ding, X. Y. Shi, B. Y. Luan, and M. Li, "Ensemble learning regression for estimating unconfined compressive strength of cemented paste backfill," IEEE Access, vol. 7, pp. 72125-72133, 2019.

[5] S. Cao and W. Song, "Effect of filling time on the mechanical strength and ultrasonic properties of cemented tailing backfill," International Journal of Mineral Processing, vol. 166, pp. 62-68, 2017.

[6] G. Xue, E. Yilmaz, W. Song, and S. Cao, "Mechanical, flexural and microstructural properties of cement-tailings matrix composites: effects of fiber type and dosage," Composites Part B: Engineering, vol. 172, pp. 131-142, 2019.

[7] T. Belem and M. Benzaazoua, "Design and application of underground mine paste backfill technology," Geotechnical and Geological Engineering, vol. 26, no. 2, pp. 147-174, 2008.

[8] S. Cao, E. Yilmaz, and W. Song, "Dynamic response of cement-tailings matrix composites under SHPB compression load," Construction and Building Materials, vol. 186, pp. 892-903, 2018. 
[9] G. Xue, E. Yilmaz, W. Song, and S. Cao, "Analysis of internal structure behavior of fiber reinforced cement-tailings matrix composites through X-ray computed tomography," Composites Part B: Engineering, vol. 175, Article ID 107090, 2019.

[10] C. Qi, Q. Chen, A. Fourie, J. Zhao, and Q. Zhang, "Pressure drop in pipe flow of cemented paste backfill: experimental and modeling study," Powder Technology, vol. 333, pp. 9-18, 2018.

[11] S. Cao and W. Song, "Effect of filling interval time on longterm mechanical strength of layered cemented tailing backfill," Advances in Materials Science and Engineering, vol. 2016, Article ID 9507852, 7 pages, 2016.

[12] E. Yilmaz, T. Belem, and M. Benzaazoua, "Study of physicochemical and mechanical characteristics of consolidated and unconsolidated cemented paste backfills," Gospodarka Surowcami Mineralnymi-Mineral Resources Management, vol. 29, no. 1, pp. 81-100, 2013.

[13] G. Xue, E. Yilmaz, W. Song, and E. Yilmaz, "Influence of fiber reinforcement on mechanical behavior and microstructural properties of cemented tailings backfill," Construction and Building Materials, vol. 213, pp. 275-285, 2019.

[14] M. Benzaazoua, T. Belem, and E. Yilmaz, "Novel lab tool for paste backfill," Canadian Mining Journal, vol. 127, no. 3, pp. 31-32, 2006.

[15] B. Koohestani, A. Koubaa, T. Belem, B. Bussière, and H. Bouzahzah, "Experimental investigation of mechanical and microstructural properties of cemented paste backfill containing maple-wood filler," Construction and Building Materials, vol. 121, pp. 222-228, 2016.

[16] H. Jiang, Z. Qi, E. Yilmaz, J. Han, J. Qiu, and C. Dong, "Effectiveness of alkali-activated slag as alternative binder on workability and early age compressive strength of cemented paste backfills," Construction and Building Materials, vol. 218, pp. 689-700, 2019.

[17] E. Yilmaz, "Advances in reducing large volumes of environmentally harmful mine waste rocks and tailings," Gospodarka Surowcami Mineralnymi-Mineral Resources Management, vol. 27, no. 2, pp. 89-112, 2011.

[18] G. Xue, E. Yilmaz, W. Song, and S. Cao, "Compressive strength characteristics of cemented tailings backfill with alkali-activated slag," Applied Sciences, vol. 8, no. 9, p. 1537, 2018.

[19] A. Tariq and E. K. Yanful, "A review of binders used in cemented paste tailings for underground and surface disposal practices," Journal of Environmental Management, vol. 131, pp. 138-149, 2013.

[20] E. Yilmaz, M. Benzaazoua, B. Bussière, and S. Pouliot, "Influence of disposal configurations on hydrogeological behaviour of sulphidic paste tailings: a field experimental study," International Journal of Mineral Processing, vol. 131, pp. 1225, 2014.

[21] S. Cao, E. Yilmaz, and W. Song, "Fiber type effect on strength, toughness and microstructure of early age cemented tailings backfill," Construction and Building Materials, vol. 223, pp. 44-54, 2019.

[22] Q. Chen, Q. Zhang, C. Qi, A. Fourie, and C. Xiao, "Recycling phosphogypsum and construction demolition waste for cemented paste backfill and its environmental impact," Journal of Cleaner Production, vol. 186, pp. 418-429, 2018.

[23] E. Yilmaz, T. Belem, and M. Benzaazoua, "One-dimensional consolidation parameters of cemented paste backfills," Gospodarka Surowcami Mineralnymi-Mineral Resources Management, vol. 28, no. 4, pp. 29-45, 2012.

[24] M. Torsaeter, J. Todorovic, and A. Lavrov, "Structure and debonding at cement-steel and cement-rock interfaces: effect of geometry and materials," Construction and Building Materials, vol. 96, pp. 164-171, 2015.

[25] W. Xu, X. Tian, and P. Cao, "Assessment of hydration process and mechanical properties of cemented paste backfill by electrical resistivity measurement," Nondestructive Testing and Evaluation, vol. 33, no. 2, pp. 198-212, 2018.

[26] M. Fall and O. Nasir, "Mechanical behaviour of the interface between cemented tailings backfill and retaining structures under shear loads," Geotechnical and Geological Engineering, vol. 28, no. 6, pp. 779-790, 2010.

[27] S. Cao, E. Yilmaz, and W. Song, "Evaluation of viscosity, strength and microstructural properties of cemented tailings backfill," Minerals, vol. 8, no. 8, p. 352, 2018.

[28] R. Janeliukstis, A. Clark, M. Papaelias, and S. Kaewunruen, "Flexural cracking-induced acoustic emission peak frequency shift in railway prestressed concrete sleepers," Engineering Structures, vol. 178, pp. 493-505, 2019.

[29] M. Qin, K. Wang, K. Pan, T. Sun, and Z. Liu, "Analysis of signal characteristics from rock drilling based on vibration and acoustic sensor approaches," Applied Acoustics, vol. 140, pp. 275-282, 2018.

[30] H. K. Kim and H. K. Lee, "Influence of cement flow and aggregate type on the mechanical and acoustic characteristics of porous concrete," Applied Acoustics, vol. 71, no. 7, pp. 607-615, 2010.

[31] M. Haggui, A. El Mahi, Z. Jendli, A. Akrout, and M. Haddar, "Static and fatigue characterization of flax fiber reinforced thermoplastic composites by acoustic emission," Applied Acoustics, vol. 147, pp. 100-110, 2019.

[32] A. Thirumalaiselvi and S. Sasmal, "Acoustic emission monitoring and classification of signals in cement composites during early-age hydration," Construction and Building Materials, vol. 196, pp. 411-427, 2019.

[33] P. Feng, F. Dai, Y. Liu, N.-W. Xu, and H.-B. Du, "Coupled effects of static-dynamic strain rates on the mechanical and fracturing behaviors of rock-like specimens containing two unparallel fissures," Engineering Fracture Mechanics, vol. 207, pp. 237-253, 2019.

[34] Q. Guo, G. Rong, M. Yao, L. Cheng, J. Yang, and J. Peng, "Experimental study on acoustic emission characteristics and mechanical behaviors of thermally damaged marble," Chinese Journal of Rock Mechanics and Engineering, vol. 34, no. 12, pp. 2388-2400, 2015.

[35] H. R. Li, C. Yang, W.-G. Zhao, B. Liu, and X.-Y. Yin, "Experimental studies of failure characteristics and evolution laws of ultrasonic velocity and acoustic emission for salt rock under triaxial loading," Rock and Soil Mechanics, vol. 37, no. 9, pp. 2458-2476, 2016.

[36] X. Xue, Y. Ke, Q. Kang et al., "Cost-effective treatment of hemihydrate phosphogypsum and phosphorous slag as cemented paste backfill material for underground mine," Advances in Materials Science and Engineering, vol. 2019, Article ID 9087538, 11 pages, 2019.

[37] E. Yilmaz and M. Fall, "Introduction to paste tailings management," in Paste Tailings Management, Springer, Cham, Switzerland, 2017.

[38] H. Jiang, H. Yi, E. Yilmaz, S. Liu, and J. Qiu, "Ultrasonic evaluation of strength properties of cemented paste backfill: effects of mineral admixture and curing temperature," Ultrasonics, vol. 100, Article ID 105983, 2020.

[39] A. Wu, Y. Wang, B. Zhou, and J. Shen, "Effect of initial backfill temperature on the deformation behavior of early age cemented paste backfill that contains sodium silicate," 
Advances in Materials Science and Engineering, vol. 2016, Article ID 8481090, 10 pages, 2016.

[40] E. Yilmaz, "Stope depth effect on field behaviour and performance of cemented paste backfills," International Journal of Mining, Reclamation and Environment, vol. 32, no. 4, pp. 273-296, 2018.

[41] L. Guo, W. Li, X. Yang, and W. Xu, "Sodium silicate gel effect on cemented tailing backfill that contains lead-zinc smelting slag at early ages," Advances in Materials Science and Engineering, vol. 2018, Article ID 8502057, 6 pages, 2018.

[42] Y. Wang, C. H. Li, and Y. Z. Hu, "Use of X-ray computed tomography to investigate the effect of rock blocks on mesostructural changes in soil-rock mixture under triaxial deformation," Construction and Building Materials, vol. 164, pp. 386-399, 2018.

[43] DZ/T. 0276.20-2015, Regulation for Testing the Physical and Mechanical Properties of Rock-Part 20: Test for Determining the Strength of Rock in Triaxial Compression, Geological and Mineral Industry Standards of the People's Republic of China, Beijing, China, 2015.

[44] JB/T. 11603.1-2013, Non-destructive Testing InstrumentsAcoustic Emission-Equipment Characterization. Part 1: Equipment Description, Ministry of Industry and Information Technology of the People's Republic of China, Beijing, China, 2015. 


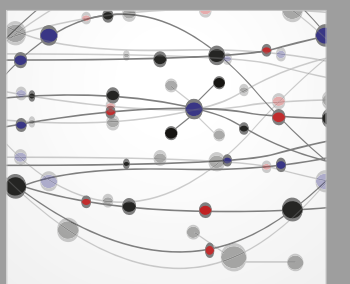

The Scientific World Journal
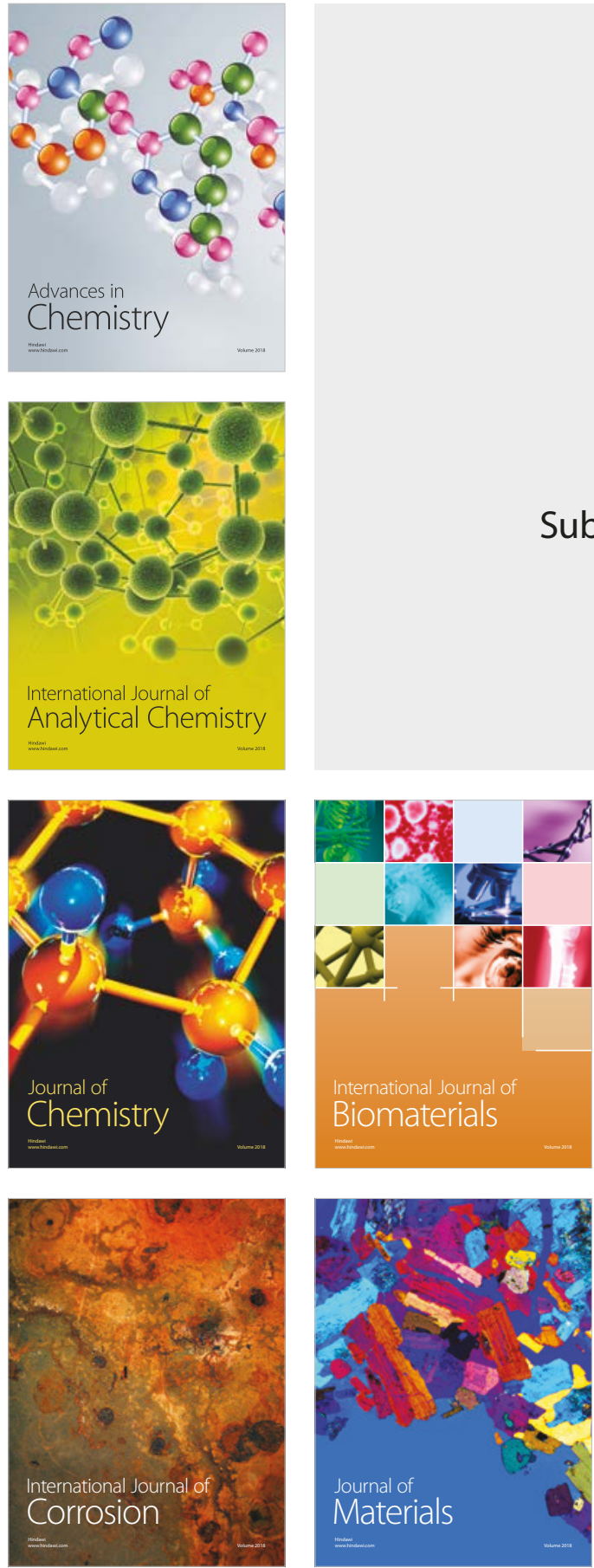

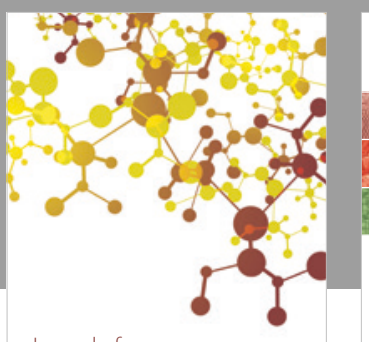

Journal of

Applied Chemistry
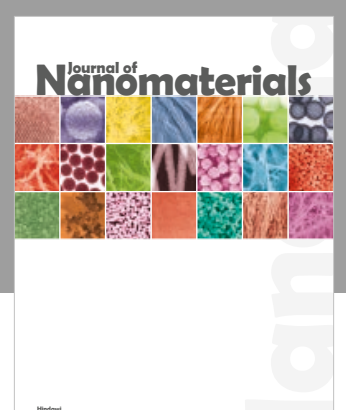

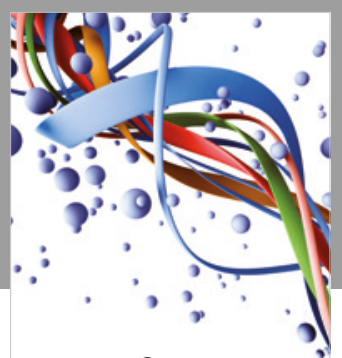

Scientifica

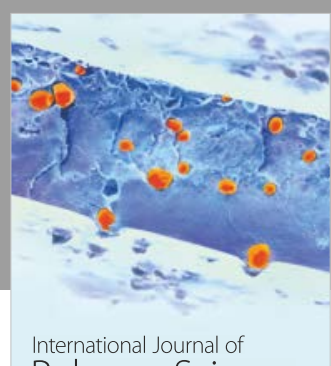

Polymer Science

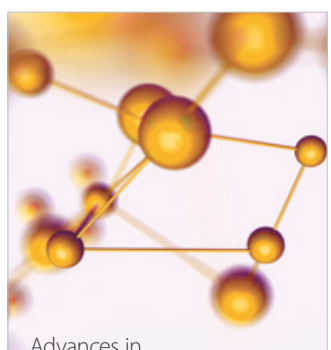

Physical Chemistry
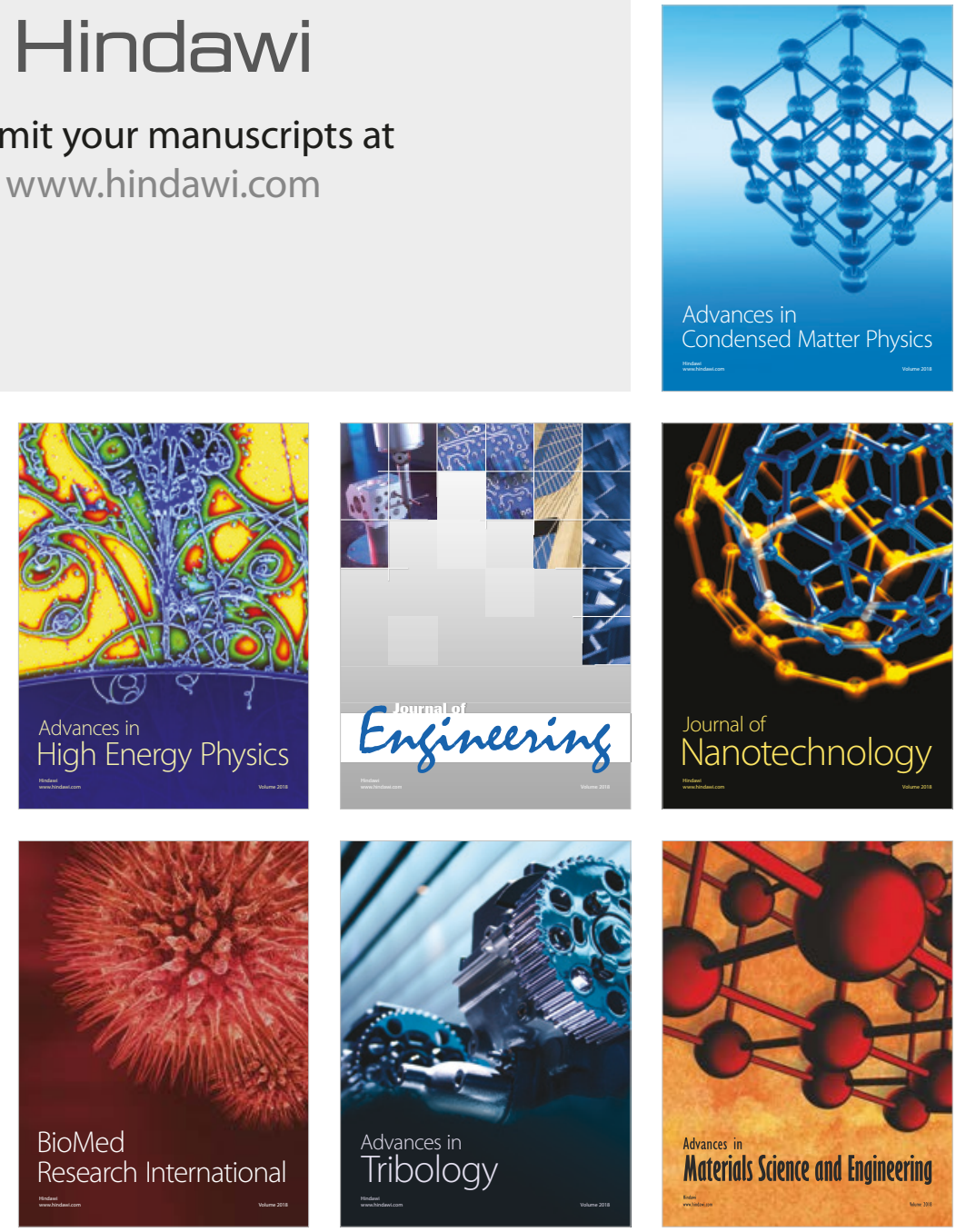